\title{
Estilo y Motivos en el Estudio Icomográlico
}

Linsayo en la metodologia de la historia del ante

$$
\text { por }
$$

Francisco stastny

Historia y Tradición.

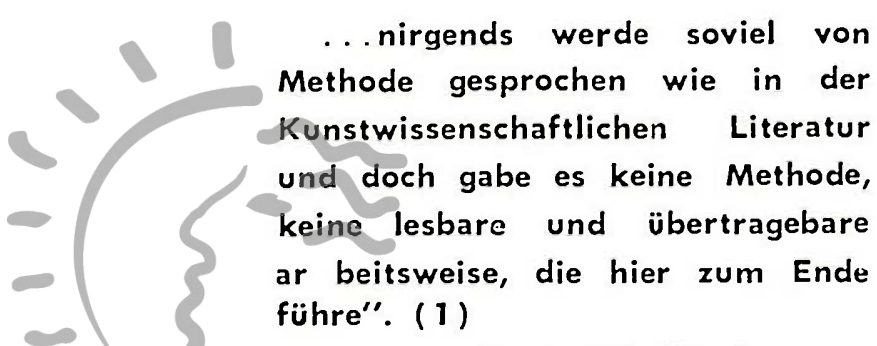

M. J. Friedlander.

La historia deloarte, en su calidad dé disciplina histórica, se ocupa de trazar cronológicamente la génesis de las obras de arte y los acontecimientos que han Godeado sundrigen. La manera de realizar en la práctica un programa tan amplio es sin duda múltiple. Según que el énfasis esté puesto sobre las obras, sobre el estilo, sobre la biografía de los artistas o sobre la historia económica y política de la época; sobre la evolución de un género o sobre la iconografía y los simbolismos filosóficos presentes, se obtendrán otros tantos resultados diferentes. No obstante, en el fondo existen algunos elementos constantes que son comunes a todas las ramas de las humanidades, y que proviene de nuestra manera original de ver el material histórico. Es decir aquella alternativa bien conocida -y quizá estereotipada- entre el acontecimiento y lo cotidiano, entre el individuo y la sociedad, el héroe y el hombre corriente, entre la creación genial y la obra rutinaria.

Expuesta de esta manera aquella oposición, que presenta el panorama histórico como una "grisaille" en la cual el diseño se 
destaca con violencia sobre un fondo de tonalidad uniforme, es sin duda una exageración; y ciertamente en el dominio de la historia política la distinción cualitativa entre el acontecimiento excepcional y el ordinario está sujeta a más de un criticismo escéptico. Pero cuando se penetra en el campo de la historia del arte el juicio cualitativo se encuentra a la base de todo el sistema. "Cada obra es una batalla por la conquista de la belleza. El historiador debe decir porqué esa batalla fue ganada o perdida", en las palabras de J. Laran (2). El día que se pierda fe en la posibilidad de una distinción valorativa, el día en que no se aprecie la diferencia entre Rembrandt y Carlo Dolci (3), ese día la historia del arte dejará de existir porque las obras habrán dejado de tener un significado.

Podemos, pues, definir provisoriamente uno de los objetivos básicos de la historia del arte diciendo que ésta se propone descubrir y trazar con claridad las relaciones sutiles, las diferencias cualitativas, los contactos y los vínculos de causa y efecto entre la obra genial y la tradición, entre el creador de excepción y los otros artistas, para obtener asi una comprensión mejor de aquello que en la obra maestra parece desafiar toda comprensión.

El método clásico para alcanzar ese objetivo ha sido atacar el estudio de la vida de los artistas en monografías siempre más perfectas y detalladas. Llega un momento, sin embargo, en que, en la medida de lo posible, las lagunas en la cronología están colmadas, en que la evolución de las obras es conocidalen detalle, en que todas las evidencias exteriores han sido recogidas y, más aún, los caracteres estilísticos han sido descritos en un lenguaje en que las sutilezas del idioma desafían a las imágenes. No obstante el genio y aquello que cuenta en su obra todavía permanecen en gran parte ocultos, como si para resaltar la silueta de un dibujo se hubiese pasado y repasado el lápiz sobre los contornos hasta que las líneas perdiesen todo carácter.

Aunque una claridad local ilumina, gracias a este método monográfico, la vida y la obra de los artistas individualmente, el cuadro general en su calidad de panorama histórico se resiente con ese procedimiento. En vez de la visión de conjunto que es capaz de englobar bajo un mismo horizonte todos los detalles de la evolución histórica, se siente una inercia que tiende a detenerse en los pormenores locales y a convertir la historia en una adición de monografías, en un centón en que falta aquella parte esencial, aquel tejido con- 
juntivo que es el que revela las relaciones que unen un elemento con el otro.

Para contrarrestar ese efecto uno puede preguntarse si no sería deseable abandonar momentáneamente al artista para ocuparse más detenidamente de la tradición de la cual ha surgido y frente a la cual se destaca. Pero, ¿en qué consiste la tradición y cómo será posible asirla para hacerla visible y palpable en el estudio histórico?

\section{Tradición y Estilo}

Sin duda el primer efecto cle ese cambio cle enfoque será una concentración de la atención sobre las obras. Hacer "hablar" al objeto es una recomenclación que se ha convertido en un iugar común en los manuales de historia del arte. $Y$ esa preocupación ha desarrollado más de un método que permite estudiar a la obra en un contexto original, en que se presenta liberada de la armazón biográfica, creándole asi una nueva dimensión y otorgando horizontes inesperados a nuestra comprensión del fenómeno artístico.

Los últimos ochenta años han visto una gran renovación en ese sentido y la aparición de diversos sistemas metodológicos innovadores. Métodos iconográficos como el de E. Male, quien se ocupó de buscar las relaciones entre las artes plásticas y los textos literarios del medioevo; o como el de Julius von Schlosser, Aby Warburg y su escuela, que culmina en la ciconology" de E. Panofsky, la cual se propone extrāer gdapluzto̊dolo quenunarpintura o una escultura puede reflejar del pensamiento de la época en que fue creada $\sin$ olvidar por eso su valor estético. O como los métodos representados en los escritos considerablemente anteriores de Riegl y de Woelfflin, dedicados a la comprensión del estilo y a las leyes de la evolución formal.

El éxito de los discípulos de los dos últimos historiadores (como Dvorak, Worringer, Sedlmayr), dio por resultado que gran parte de los esfuerzos que durante varias generaciones los estudiosos dedicarorn a la creación de una metodología racional de la historia del arte, fuesen dirigidos al problema del estilo. En efecto, en su vasta complejidad y en ese carácter inasible que hace que su definición esté siempre por recomenzar, el estilo parecía ofrecer la respuesta a casi todas las interrogantes. La germinación y génesis de la obra, su envoltura formal, su relación con las obras que la 
han precedido y su posición en el contexto histórico, su sıgnificado en el presente $y$ su influencia sobre las generaciones del futuro. Todo eso parece que se resolverá con una claridad de cristal el día que hayamos sido capaces no sólo de describir si no también de comprender el por qué cle los cambios de estilo.

Sin embargo si se observa el problema con mayor atención se verá que cuando se trata cle obtener una definicion más precisa de la tradición artística, una metodología basada en el análisis estilístico no parece ser la más apropiada. Estilo y tradición son conceptos contrarios que una confusión de términos identifica a menudo. El estilo tiene un carácter esencialmente temporal. Nada más inconsistente que él. Durante décadas se le ve avanzar con esfuerzo y a pasos cada vez más apresurados y temerarios hacia lo que parece ser su madurez. $Y$ apenas llegado al punto culminante se desccmpone con un frenesí inexplicable como si la cima alcanzada fuese el filo de una espada. Una contínua oscilación, una perpetua evolución parece ser el destino de la "vida de las formas".

Gracias al estilo es posible reconocer la época en que una obra fue creada. "... Ningún arte está libre de convenciones... Son estas convenciones... las que permiten al historiador del arte de fechar una obra...; (y) es su totalidad la que conforma aquello que llamamos 'estilo' en una pintura". (4) Es por eso que una pintura romana de 1510 se distingue de una de 1530. El estilo expresa, pues, aquel̄orgue esctípicol denmomento histórico, aquello que es pasajero. Lejos de expresar la tradición, es el sello del momento.

\section{Motivos: héroes $y$ ángeles}

Existe otro aspecto en el mundo de las formas que refleja mucho más apropiadamente aquello que es durable en las artes plásticas. Nos referimos al "motivo", aquel elemento formal que sobrevive a través de los cambios de estilo y que representa en cierta manera la "unidad decimal", la molécula, el ladrillo, en la construcción de una obra de arte. Como el propio ladrillo, cuya forma ha sido transmitida de generación en generación desde los albores de la civilización y que ha sido empleado en la estructura de edificios extremadamente diversos por los diferentes pueblos que lo heredaron, así también existen motivos gráficos cuyos orí- 
genes remontan a tiempos casi tan lejanos y que han viajado a través de la historia $y$ de los continentes y que aún persisten entre nosotros manteniendo lo esencial de su aspeco original. Tal el caso extraordinario de los doce signos del zodíaco que tomaron forma en la imaginación de los sacerclotes-astrónomos "baru" de Babilonia y que aún circulan hoy día, no sólo entre los adeptos de la astrología, sino en toda clase cle usos decorativos.

No todas las imágenes han gozado de una existencia tan prolongada y tan ubícua como la de las doce posiciones del zodíaco. Por lo común sucede lo contrario: aunque dilatada, un día la vida de una imagen encuentra un término. Y lo que es más, a través de los avatares que atraviesa, su significado puede variar múltiples veces. En las palabras de F. Saxl: ". . images with a meaning peculiar to their own time and place, once created, have a magnetic power to attract other ideas into their sphere; ... they can suddenly be forgotten and remembered aoain after centuries of oblivion". (5)

Así sucede con ese motivo extraño de la lucha entre el héroe y la bestia, que se origina en los más antiguos sellos-cilindricos de Sumeria, y que parece representar el eco que dejó en el espíritu humano el combate formidable que debió haber sido la domesticación del toro. A pesar del lugar predominante que ocupa en la iconografía del Cercanooriente, seeignora ebsentido religioso exacto de esta imagen. De Mesopotamia emigra hacia Grecia, donde es perfeccionada en la forma: el héroe hinca su rodilla en la espalda torcida del toro y lo sujeta por los cuernos con ambas manos. El vencedor ahora se llama Heracles, Niké, Teseo o es un lapita en batalla con los centauros. Sus combates son episodios menores en la mitología griega. Pero pronto el motivo volverá a triunfar en la imaginación de los pueblos. Un nuevo culto proveniente de Persia - $y$ con raíces profundas en India- se difunde con vigor en el Imperio Romano en los primeros siglos de la Era. Es el culto de Mitra, dios de la luz y de la verdad que desciende bajo tierra para sacrificar el toro de la fertilidad y que promete, de manera similar al cristianismo, la salvación de los justos y la inmortalidad del alma. En efecto, la religión de Mitra fue el gran rival de la fe en Cristo en aquelos siglos decisivos en la historia del Occidente. En la multitud de pequeños templos subterráneos dedicados al mitraísmo se eneventra repetida sistemáticamente una imagen que ya 
nos es familiar: el héroe erguido sobre el toro falleciente le hunde un cuchillo en el cuello y apoya su rodilla sobre el flanco curvo del animal. Esta vez el héroe no es el dios barbado de Babilonia, ni Heracles, ni Teseo con el toro de Maratón, sino el dios solar Mitra.

Podría creerse que con el triunfo del cristianismo sobre la fe mitraica, el motivo del hérce ' ${ }^{\prime}$ de la bestia desaparecerá de la escena. No obstante después de un eclipse de varios siglos la imagen vuelve aparecer en el siglo $X 11$ representando a Sansón y el león. Pero esta vez su vida está contada. Ocupa una posición marginal en el arte gótico. Y por último es resucitada excepcionalmente una vez más por un escultor florentino del renacimiento, Antonio Roseilini, quien sin duda se inspiró cle uno de los relieves clásicos. Con el siglo XVI, el comienzo del humanismo y la sed de conocimiento arqueológicos, la figura de Mitra termina su carrera ilustrando manuales de religión comparada. Esa es su última y definitiva aparición en el mundo de las formas.

Otro ejemplo extremamente interesante de la tenacidad de una imagen es la de un motivo que hos es muy familiar: el motivo del ángel alado que puebla nuestros cuadros religiosos. ¿Qué aspecto tienen los ángeles? ¿Y desde cuándo están presente en el arte cristiano?

Originalmente "ángel" proviene del griego y tanto en griego como en hebreo el término significa "mensajero". Una lectura cuidadosa de los textós sagrados Mostrarátnozsólo que los "mensajeros divinos" no poseen alas, sino que el imaginarlos alados contradice a ménudó el sentido de las historias" bíblicas. Así, las múltiples veces que los "hombres de Dios" deben probar con subterfugios e infinita paciencia su esencia divina a los patriarcas que visitan en el Antiguo Testamento. Si dos enormes alas brotasen de sus hombros no habrían todas esas dificultades de identificación y de credenciales. Véase por ejemplo las historias de Manoah, de Gedeón, de Josué o la de Lot.

Si por añadidura, nos dirigimos al arte paleo-cristiano, nuestras sospechas se verán confirmadas. Los artistas de aquellos días, fieles al sentido literal del texto bíblico, habían representado a los ángeles como simples mensajeros humanos, sin alas. Será sólo en la primera mitad del siglo $V$ que por primera vez, en un mosaico de St. María Maggiore de Roma, aparecen ángeles alados rodeando a la Virgen. 
Pero, ¿de dónde proviene entonces la figura humana alada? Una vez más se trata de un motivo profundamente arraigado en el Cercano Oriente, que fue adaptado en la forma de Niké, la Victoria, por Grecia, y que floreció muy particularmente bajo el Imperio Romano debido a la importancia que la victoria tenía para una civilización guerrera. Lo lógico hubiera sido que con el hundimiento del Imperio y la oficialización de una religión que predicaba la paz sobre la tierra, esta figura alada, que traía a la memoria el esplendor del paganismo, fuese perdida en el olvido. En cambio ia fuerza de la imagen era tal que conquistó el pensamiento cristiano e "hizo que la gente imagine cosas que no estaban en los textos escritos o inclusive cosas contrarias a ellos" (6). Desde el siglo $V$, cuando la metamorfosis de Victoria pagana en ángel tuvo lugar, la imagen alada se arraigó profundamente en el arte religioso subsistiendo plena de vitalidad hasta nuestros días.

Las únicas excepciones en ese largo lapso provienen de dos lectores apasionados e imaginatiyos de la Biblia: Miguel-Angel y Rembrandt. Desgraciadamente nos falta espacio en esta nota para entrar en el detalle de la historia de esas dos rebeliones contra una tradición milenaria.

\section{Tipos lconográficos}

Los ejemplosiquejacabamos de describir someramente nos permitirán analizar más detenidamente el rol que juegan los motivos y sobre todo observar Pasl felaciones queVos Onen a los otros elementos componentes de una obra de arte. En primer lugar, tanto en el caso del héroe con el toro como en el caso de los ángeles, hemos podido darnos cuenta de la independencia que muestra el motivo gráfico frente a la idea. La imagen permanece, el contenido o el tema en que está inscrita, varía. Lo que es más, un mismo motivo puede servir simultáneamente a diversos temas, como sucede en el caso de Hércules, Teseo, La Niké sacrificadora y otros temas en el arte clásico heleno todos los cuales asumen la imagen perfeccionada del héroe con el toro. Por otro lado, así como un motivo puede variar sus contenidos, así también un tema puede alternar sus motivos sin verse afectado por ello. $O$ sea que temas y motivos se comportan con perfecta independencia el uno en relación al otro. El ejemplo más notorio de esas mútuas transforma- 
ciones es el de la suerte que corren las figuras greco-romanas en el arte gótico. La forma por un lado y el contenido por otro sobreviven en la Edac' Media, pero recorriendo trayectorias enteramente diferentes. Mientras que Hércules —el tema- se ve transformado en las miniaturas medievales en un caballero andante armado de punta en blanco; el motivo gráfico de Hércules aparece dando forma a la alegoría de la Salvación en la fachada de la Basílica de S. Marcos de Venecia. (7)

No sólo que imagen e idea son mutuamente independientes, sino que debido a la inercia vital de las primeras el número de los temas - que tienen a su clisposición la riqueza inagotable de la historia y de las ideas - es muy superior a la de los motivos.

En relación directa a esto se encuentra el hecho de que los temas poseen por lo común una vida más breve que los motivos. Son más numerosos, pero fallecen antes. El dios Mitra concluyó su carrera en Occidente poco después del siglo IV, pero el motivo del héroe con el toro aún persiste once siglos más tarde. No obstante si detenemos nuestra mirada en una extensión más limitada del devenir histórico, se observará que temas y motivos siguen cursos paralelos unidos estrechamente en aquella compleja simbiosis que relaciona a la forma con el contenido. En el lapso de un siglo o dos el tema y las imágenes que lo conforman seguirán fieles el uno al otro, mostrando tan sóle cambios menores en su configuración formal.

Estas variantes que se manifiestan en la envoltura formal de un tema determinan ciertos patrones de agrupación que denominaremos "tipos iconográficos". Cuando un artista debe representar un asunto determinado sigue inconscientemente esos patrones. El lenguaje gráfico aprendido, su educación, la "voluntad de forma" de la época lo inducen a ello. Pero los "tipos" no son estáticos, sino que se suceden en el tiempo. Los motivos que los conforman poseen una libertad de movimiento que permite frecuentes renovaciones. Es así que de tiempo en tiempo se presentan innovaciones, surgen nuevos motivos, otros son eliminados o los motivos tradicionales son combinados en una forma novedosa en la composición general de la obra, satisfaciendo una exigencia de expresión que será recogida y seguida por todos los artistas del momento. En esta manera, pues, se describe una serie de patrones iconográficos que 
forme. Esto era necesario para destacar algunos rasgos objetivos se suceden cronológicamente y que trazan la cadena de una evolución formal en la historia del tema.

Así llegamos a un punto en que progresando del motivo al contenido o tema, y del tema a la composición, nuestro campo de investigación abarca gradualmente la obra de arte entera; proyectando, inclusive, como veremos más tarde, alguna luz sobre el evasivo problema del estilo. Con la definición del tipo iconográfico hemos alcanzado el punto culminante, del procedimiento metodo lógico aquí en discusión. Son los tipos los que nos permitirán una descripción y una comprensión detallada de la tradición artística -que era el objetivo que nos habíamos propuesto al comienzo de este ensayo. Es cierto que enfocado de este modo el resultado será un estudio en profundidad más que en extensión. Seguir el desarrollo de un solo tema -o de un grupo de temas- a través de su evolución tipológica dará por resultado un panorama similar al que ofrece el "corte" arqueológico ("cross-section") en una excavación; mostrará una estratografía precisa y detallada, pero estrictamente limitada a una fracción de terreno. Hasta qué punto sus conclusiones podrán ser extendidas a un área más vasta o a toda una época, dependerá en gran parte de la selección correcta del lugar a ser excavado, o sea del tema escogido.

Hasta este momento hemos tratado nuestro campo de estudio como si efectivamenteofúese un material arqueológico en el cual el individuo creador desaparece bajo la masa de una producción uniforme. Esto era necesario para destacar algunos rasgos objetivcs de la elaboración artística. Pero en realidad nuestra atención estará concentrada con igual interés sobre el artista como sobre la tradición colectiva de la cual éste depende y frente a la cual se destaca. Dentro de los límites del vocabulario formal que le es familiar, el artista es libre de escoger, de crear y de innovar. Gozando de "libertad... en la realización plástica de sus ideas, inconscientemente (los artistas) se conforman a la tradición, y su significado reside precisamente en la manera en que sus obras están simultáneamente investidas por la tradición y opuestas a ella", escribe D. Robb. (8) Es por eso que es sumamente importante comprender que al definir el tipo iconográfico como un prototipo formal que es seguido por todos los artistas de una época y de un país - o de una región determinada_, que el tipo no es un esquema 
imitado mecánicamente; no es un "cliché" impreso con el rigor de un postulado sobre cada obra producida. Este punto ya fue destacado en 1920 por F. Stahl (9) quien lo subrayó con una cita de $\mathrm{H}$. Woelfflin, referente a que en lo histórico "no existe nada concluso; todo... está sujeto a un continuo devenir, pero es necesario decidirse a asir las multiplicidades en un punto fértil y dejarlas jugar en contraste las unas contra las otras". (10) Aquel punto fértil, por las comparaciones que permite del fenómeno histórico de apariencia multifacética, es en nuestro caso el tipo iconográfico.

Desde el instante, pues, en que los tipos iconográficos son reconocidos como los modelos generales de composición seguidos por todos los artistas de la época, su descripción consecutiva dará por resultado un claro esbozo de la tradición artística. Aquellos elementos que están presentes en la tradición de una "escuela" serán enumerádos y traídos metódicamente a la luz analizando el origen y la filiación de los motivos/significativos que la conforman. La aparición de un nuevo tipo en la historia de un tema estará marcada por las transformaciones formales internas a que nos hemos referido más arriba. $Y$ si ahora examinamos esas modificaciones se hará evidente que los nuevos componentes se originan en una de tres fuentes principales: 1) de una tradición local anterior, inspirándose en obras del pasado; 2 ) de una influencia extranjera que se impone por sulprestigio o su adaptabilidad; 3) o de una innovación local «Jorge Puccinelli Converso»

No nos es posible entrar aqui en el detalle de cada uno de estos modos de renovación. La función y la importancia del arcaísmo o de la fidelidad a las imágenes de los maestros del pasado; la afinidad que une dos centros relacionados por la difusión (11) o el efecto renovador de los motivos transplantados sobre el espíritu creativo del centro que recibe las influencias, son problemas que no podemos englobar en este estudio. Sin embargo debemos tomar en consideración más largamente el tercer punto: las innovaciones locales.

\section{El Artista y su Tradición}

Cuando nos referimos a la manera en que esta metodología nos permite tomar en consideración simultáneamente al artista y a su tradición, no llegamos a describir cómo estas complejas rela- 
ciones son clarificadas gracias a una comparación del lipo iconográfico con la creación individual. Ante la masa de artistas cuyas obras se conforman con mayor o menor fidelidad a las indicaciones del tipo, aparecerán otros que se destacan en oposición al modelo generai. A menudo aquellos rebeldes son los innovadores de genio cuyas conquistas serán más fácilmente definibles al ponerlas frente a frente a la medida común del tipo. Por un simple proceso de análisis formal será posible distinguir el elemento de invención personal, la parte debida al arte del pasado y, sobre todo, será posible destacar en qué medida aquello que a primera vista aparece como pura originalidad no es en último término sino reelaboración de componentes pertenecientes a la tradición.

Por lo común - pero no en todos los casos, es necesario insistir en esto- aquellos innovadores son los "jefes" de escuela, cuyas obras poseen la vitalidad de animar un nuevo tipo y que serán seguidos por generaciones de artistas. Un Duccio, un Giotto, un Rogier van der Weyden, un Miguel-Angel, pertenecen a esa familia de creadores. Existen otios artistas cuyas obras se alejan sistemáticamente de los tipos iconográficos reinantes, como si un impulso de originalidad y de contradicción los llevase a producir creaciones que ocupan una posición de pura excepción. Así como ellos no siguen la corriente estilística de la época, así tampoco serán seguidos por sus sucesores. Son las excepciones que confirman la regla, y que, más quelnada, prueban ClCelementode libertad individual que reina en todo lo histórico. Pocas obras más libres que los grabados de juventud de Lucas de Leyde o que algunas pinturas de $\checkmark a n$ Eyck, de Rembrandt o de Hércules Seghers.

\section{Calidad y Origina'lidad}

Es importante, sin embargo, tomar en cuenta el hecho fundamental cle que la originalidad inventiva no es en sí un signo de calidad. El artista que se aleja del patrón establecido no es, por ese simple motivo un maestro de genio. $Y$ viceversa, el artista fiel al tipo tradicional no debe ser considerado por ese apego a las normas un creador mediocre. La calidad de una obra no puede ser juzgada — como se hace a menudo en la crítica contemporáneapor un método tan simplista de apreciación valorativa. La originalidad iconográfica - lo que en la terminología especializada se llama 
la habilidad de "ilustración" - no es un índice de jerarquía estética. Un ejemplo típico de esta situación es la de Quentin Metsys y Jan Gossaert, dos pintores flamencos casi contemporáneos. El primero es uno de aquellos artistas de transición -como Pisanello en Verona- que son difíciles de ubicar en la historia: ¿es el último de los antiguos o el primero de los modernos? Lo cierto es que su arte, aunque considerablemente renovado en el "tratamiento" técnico, todavia permanece en gran parte fiel a los temas y a la iconografía del siglo $X V$. Frente a él, Gossaert, nacido diez años más tarde, presenta una obra llena de novedades y de importaciones de Italia. Sin embargo, a pesar de la posición considerable que Mabuse ha obtenido en los recientes escritos críticos acerca de la pintura flamenca, todavía podemos decir sin exageración que Metsys es un artista a la vez más completo y de mayor sensibilidad. Su superioridad se verá resaltada aún más si se le compara a un característico "ilustrador" como Martin van Heemskerck, cuya obra pertenece a un nivel sensiblemente inferior, no obstante su múltiple originalidad iconográfica. Queda, pues, establecido que así como es posible encontrar artistas de primera línea que son tradicionalistas, (en España, Zurbarán es un caso típico de combinación de maestría con falta de inventiva); igualmente existen "ilustradores" muy fértiles en la producción de composiciones novedosas, pero pobres en su rendimiento artístico.

Definida la linea dela tádición que permanece incambiada a través de las variaciones de épocaly de forma, es, posible hacer referencia brevemente a un último aspecto: a la relación entre el tipo iconográfico y el estilo. Pocas experiencias son más útiles para comprender aquel fenómeno evanescente - aquel "sistema de formas" (12) - que es el estilo, que la comparación de las diferencias y las similitudes que presenta un mismo tipo o, mejor aún, un mismo motivo, figurado en estilos tan divergentes, como son, por ejemplo, el estilo de los primitivos flamencos del siglo $X V$ y el estilo de Rubens. Tales casos existen y la tradición ininterrumpida que liga aquellos dos puntos extremos de la pintura en los Países Bajos puede ser observada pasando, aún en otra envoltura estilística, por las obras de artistas menores del siglo XVI. Desde el arte medieval hasta el más pleno barroco el puente de la tradición traza una línea contínua cuyo conocimiento es esencial para la comprensión del fenómeno artístico. 
Así llegamos al fin de esta investigación. Otros problemas y muchas interrogantes podrian ser consideradas todavía en relación al circulo de ideas expuestas; pero descle el ángulo exclusivo de nuestra disciplina hemos satisfecho - en la medida de nuestras posibilidades - las interrogantes que nos habíamos planteado. El método aquí descrito no pretende ser exhaustivo. Sobre la base de conceptos bien conocidos hemos ensayado de introducir un sistema que permita obtener el objetivo clásico de la historia del arte: de otorgar una imagen clara de la evolución artística de un período, poniendo énfasis especial en las relaciones que unen a los artistas con su tradición estética.

Y es por eso también que no es el amor de la paradoja el que nos llevó a citar a Friedlander a la cabeza de estas notas; sino el deseo de que sus palabras sirvan como una advertencia liminar. En último término lo que cuenta no son los métodos -éstos no poseerán jamás el valor de caminos indiscutibles en el dominio de las humanidades. No existen métodos malos y buenos; sino tan sólo buenos y malos historiadores.

\section{Epílogo}

Las conclusiones que hemos delineado en estas páginas surgieron a la luz de meditaciones sobre la problemática planteada por el estudio de la pintura y del arte colonial.

En efecto, "Ūométódoccómol èlCdescritosses adapta iclealmente a épocas en las cuales el arte se mueve en el anonimato. La ausencia de nombres y de fechas precisas, la abundancia de obras y la pobreza de referencias documentales es una dificultad que pone a prueba la capacidad de análisis histórico. Un método de carácter iconográfico permite enfrentar esas dificultades ofreciendo un asidero al problema. Con la organización "tipológica" se introduce un orden, que es el paso previo a la comprensión y a la sistematización.

Pero este método es asimismo útil en otras circunstancias y puede ofrecer una visión renovada de períodos, muy alejados del anonimato medieval, en los cuales reinan artistas bien conocidos.

Se ha dicho a menudo que debería escribirse un dia una historia del arte sin nombres. Una historia que diera preferencia al "hecho artístico" y que resaltara las corrientes subterráneas que condicionan la génesis cle las obras de arte. Bajo esas circunstan- 

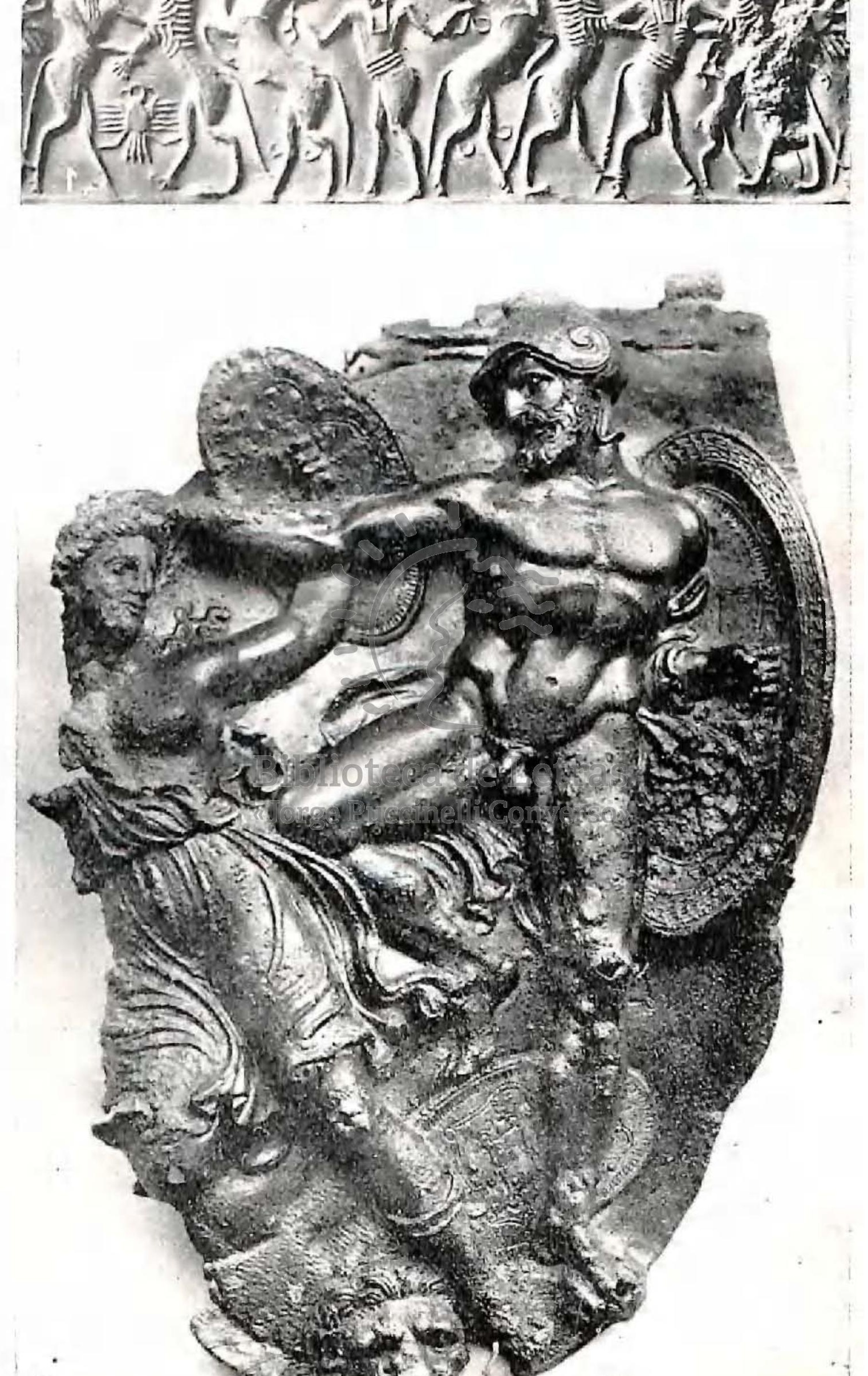
isios

of

उत्राय arist

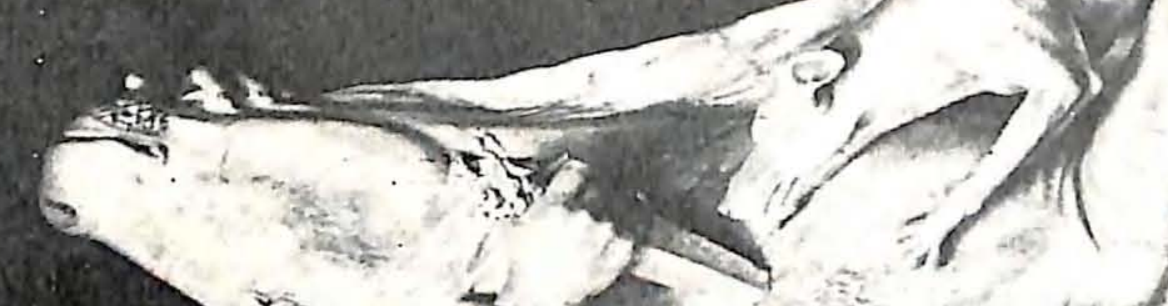
,

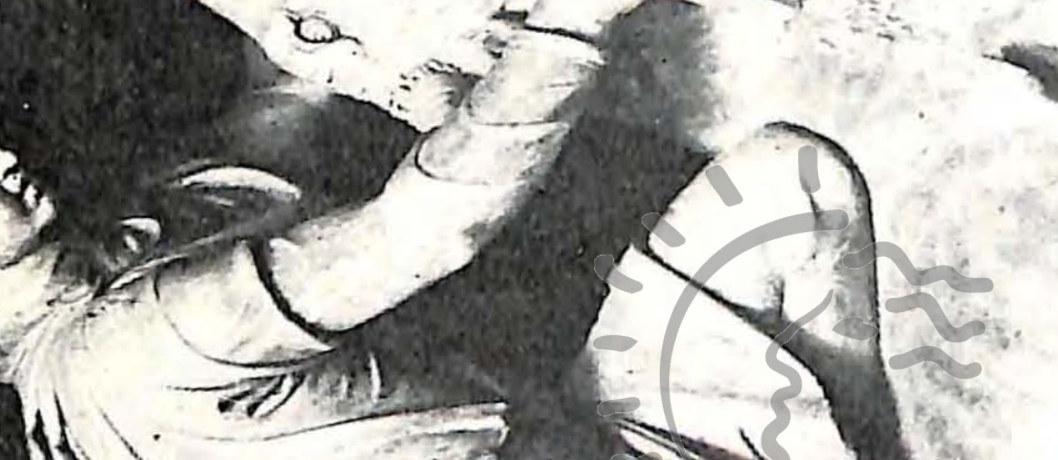

त्रा1

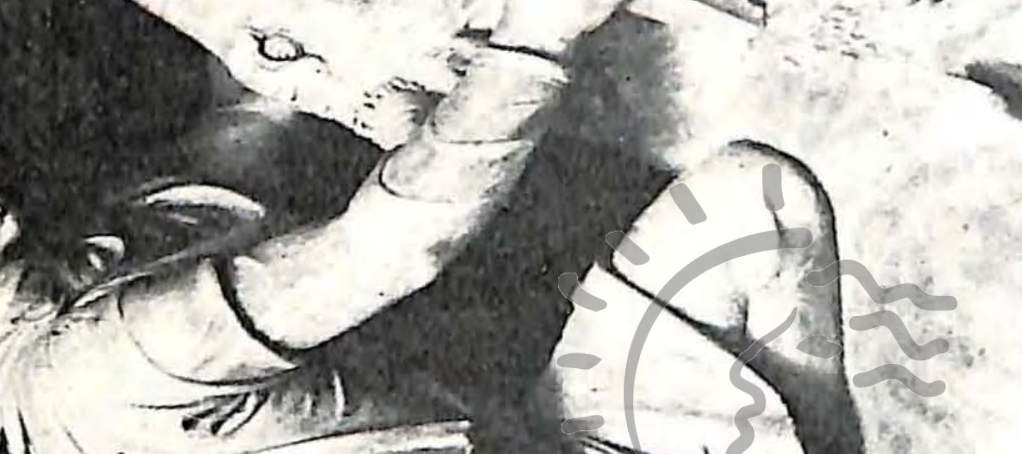

$1 \rightarrow \infty \rightarrow+2$

W1

$(-1)$

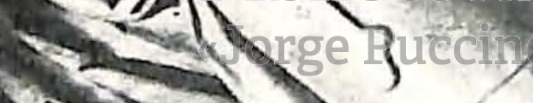
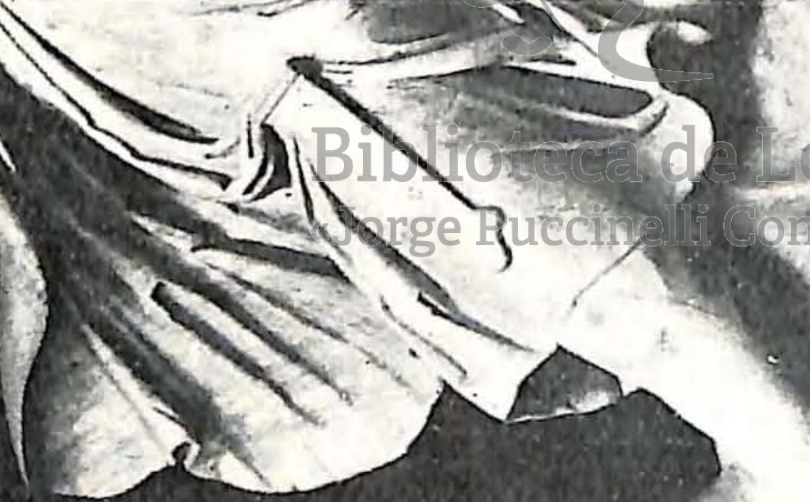


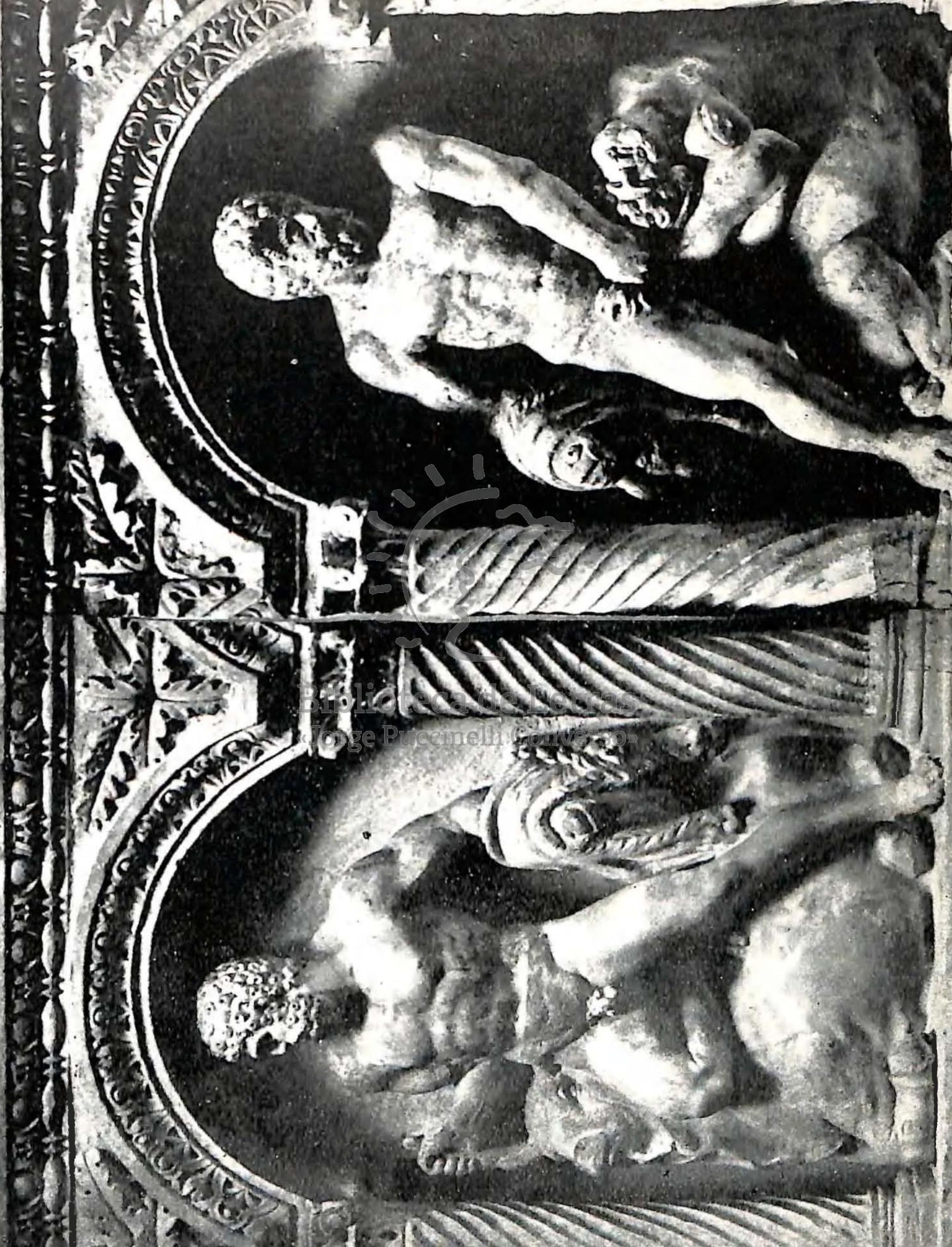




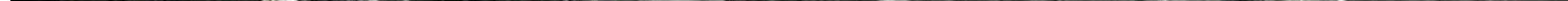


cias el investigador tendría que agudizar su sentido crítico y basarse exclusivamente en el testimonio de las obras sin dejarse cegar por la aureola de prestigio que los nombres ilustres depositan sobre las creaciones que patrocinan.

La historia iconográfica, como ha sido planteada aqui, es una aproximación hacia ese ideal extremo. Presenta la ventaja esencial de permitir atravesar sin dificultad las fronteras erizadas de espinas que separan la "obra" (el conjunto de creaciones) de un maestro, cle la de otro. Otorgando de esa manera la posibilidad, no sólo de hacer resaltar con mayor claridad a la obra genial frente a la producción artística que le es contemporánea, sino de destacar la influencia histórica decisiva que puede haber tenido una pintura o una escultura de menor calidad cuya importancia habría pasado desapercibida en una historia de tipo más convencional.

\section{NOTAS}

(1) "... En ninguna parte se habla tanto de método como en la literatura de la historia del arte y sin embargo no existe ningún método, ningún sistema legible y transmisible, que, en ese campo, conduzca a la meta". M. J. Friedliender, Der Kunstkenner, Berlín, 1919, p. 12.

(2) J. Laran, L'Estampe. 2 vols. París, 1959. Introducción.

(3) No deja de ser-interesante que para Fe Wickhoff, "...Carlos Dolci, il capro espiatorio pooverbiale] deí critici d'arte, era, dopo tutto, pittore migliore di atcuni Quattrocentisti dei quali Berenson aveva catalogato le opere con tanta cura". O Kurz, Julius von Schlosser. En: Critica d'arte, XI,'XII, 1955, p. 404.

(4) E. H. Gombrich, Art and Illusion, Londres, 1962, p. 246.

(5) F. Saxl, Continuity and variation in the meaning of images: En: Lectures, London, 1957, Warburg Institute, p. 2.

(6) op. cit., p. 11-12.

(7) E. Panofsky, Studies in Iconology: humanistic themes in the art of the Renaissance. New York, 1939. Introductory.

(8) D. M. Robb, The iconography of the Annunciation in the Fourteenth and Fifteensh centuries. En: Art Bulletin, Vol. 38, Chicago, 1936, p. 520. 
(9) E. K. Stan!, Die Legende von Hailigen Riesen Christophorus. Münehen, 1920 , p. 8.

(i0) $H$. Woelfólin, Kunstgeschichte Grundbegriffe, Munich, 1916, p. 15,

(11) Ch. Sterling, La Nature Marte, París, 1952. Véase la Introducción.

(12) Meyer Shapiro, Style. En: Kroeber, Anthropology Today, Chicago, 1953, p. 287.

\section{ILUSTRACIONES}

1.-Sello cilindrico de Sumaria (2700 A. de C.). El héroe con las bestias. British Museum, Londres.

2.-El motivo del héroe perfeccionado en Grecia (Siglo IV A. de C.). Una escena del combate con las Amazonas. British Museum, Londres.

3.-Escultura romana. El dios Mitra crea el mundo sacrificando el toro de la fertilidad. El mal se introduce en su obra en la forma de un cangrejo que ataca los órganos reproductivos del animal. Museo Vaticano, Roma.

4.-Sarcófago romano con los trabajos de Hércules donde se repite el motivo del héroe ycla bestia.-Museo Borghese, Roma.

5.-La Victoria de Samotracia (fin siglo IV A. de C.), predecesora del ángel cristiano. Museo de Louvre, París.

6.--N. Poussin: El ángel de la Anunciación. 1657. National Gallery, Londres. Típica representación del ángel en la pintura religiosa del siglo $X V \| I$. Compárese con la figura anterior. 